\title{
The impact of ADHD symptoms and global impairment in childhood on working disability in mid-adulthood: a 28-year follow-up study using official disability pension records in a high-risk in-patient population
}

\author{
Marianne Mordre ${ }^{1 *}$, Berit Groholt ${ }^{2}$, Berit Sandstad ${ }^{3}$ and Anne Margrethe Myhre ${ }^{4}$
}

\begin{abstract}
Background: Individuals with ADHD have been associated with more employment difficulties in early adulthood than healthy community controls. To examine whether this association is attributable specifically to disturbance of activity and attention (ADHD) or to psychopathology in general, we wanted to extend existing research by comparing the rate of mid-adulthood working disabilities for individuals diagnosed with ADHD as children with the rate for clinical controls diagnosed with either conduct disorder, emotional disorder or mixed disorder of conduct and emotions.

Methods: Former Norwegian child-psychiatric in-patients $(n=257)$ were followed up 17-39 years after hospitalization by record linkage to the Norwegian national registry of disability pension (DP) awards. Based on the hospital records, the patients were re-diagnosed according to ICD-10. Associations between the diagnoses, other baseline factors and subsequent DP were investigated using Kaplan-Meier survival analyses and logrank testing.

Results: At follow-up, 19\% of the participants had received a DP award. In the logrank testing, ADHD was the only disorder associated with a subsequent DP, with $30 \%$ being disabled at follow-up $(p=0.01)$. Low psychosocial functioning (assessed by the Children's Global Assessment Scale) at admission uniquely predicted future DP $(p=0.04)$.

Conclusions: ADHD in childhood was highly associated with later receiving a DP. Our finding of worse prognosis in ADHD compared with other internalizing and externalizing disorders in mid-adulthood supports the assumption of ADHD being specifically linked to working disability. Assessment of psychosocial functioning in addition to diagnostic features could enhance prediction of children who are most at risk of future disability.
\end{abstract}

Keywords: ADHD, Conduct disorder, CGAS, Disability pension award

\section{Background}

Attention-deficit/hyperactivity disorder (ADHD) is generally recognized as a neurodevelopmental disorder with executive function deficits [1,2]. In numerous studies, ADHD symptoms have been found to be uniquely related to future academic difficulties, both in population-based

\footnotetext{
* Correspondence: marianne.mordre@medisin.uio.no

'Division of Mental Health and Addiction, Oslo University Hospital, P.O. Box 4959, Nydalen, 0424 Oslo, Norway

Full list of author information is available at the end of the article
}

studies [3-5], and in clinical follow-up studies [6-9]. However, in these studies, children have been followed only into adolescence and early adulthood [6-9]. This makes it difficult to conclude about the persisting disabling nature of $\mathrm{ADHD}$ symptoms. In general, there is a decline in ADHD symptoms into adulthood, but some symptoms (inattention) seem to persist $[9,10]$. To understand the long-term developmental course of ADHD, knowledge about vocational outcome in mid-life is of interest. Despite several community studies reporting 
work impairment in adults with ADHD [11-13], comparisons have been restricted to healthy non-psychiatric control groups, as in most of the clinical follow-up studies $[6,9,14,15]$. The use of healthy controls could make it difficult to determine the extent to which the poor outcome found at follow-up was likely to be a function of the severity of ADHD symptoms specifically, rather than a function of impairment related to severity of any mental disorder. This is of special importance in disorders that debut in childhood, as aspects of normal development may be suffering. There is considerable evidence that the long-term course of child-psychiatric disorders is associated with impaired functioning and continuity of symptoms into adult life [16-18].

The use of clinical controls to delineate outcome differences across childhood diagnoses could therefore be useful when examining different developmental trajectories. In general, externalizing disorders have been associated with a more negative outcome than internalizing disorders $[16,19,20]$, with the worst outcomes being reported for co-morbid states of these disorders [20-22]. However, most of these studies have addressed the diagnostic course and criminality, and less is known about employment. Few studies have tested the validity of the persistent nature of ADHD by comparing working disabilities in individuals with ADHD with those who have either internalizing or other externalizing disorders.

In one study, Barkley et al. compared the outcomes of young adults with ADHD with individuals with internalizing disorders [23]. They found that overall impairment, including poor work performance, was higher in the ADHD group than in the internalizing group. In two community-based studies, children with ADHD symptoms were reported to fare worse in academic achievement than children with conduct symptoms $[4,5]$. These studies, however, were restricted to short-term follow-up comparisons of adolescents. Other studies have been limited by using controls that resembled ADHD groups $[24,25]$, which made it difficult to draw conclusions about the specific nature of ADHD symptoms.

In sum, most studies are limited by follow-up periods that reach only into young adulthood and/or the lack of clinical control groups. Knowledge of the chronic course of work impairment into mid-adulthood relative to clinical controls is limited.

In the present study, we wanted to compare outcome differences into mid-adulthood between children with ADHD and those with either internalizing and/or other externalizing disorders in an in-patient population. Studying childpsychiatric in-patients with excessive symptom loads could delineate outcome differences among diagnostic groups. By following the individuals into their mid-thirties, and by obtaining information about disability pension (DP) awards for these individuals, we could provide a comprehensive picture of occupational disability in adults with a childhood history of severe mental disorders. We wanted to see if working disability was associated specifically with ADHD, or whether it was an experience shared with other disorders diagnosed in childhood.

We hypothesized that former child-psychiatric inpatients with ADHD would have a higher rate of working disability relative to other clinical groups. We also hypothesized that individuals with co-morbid ADHD and conduct disorder would be more disabled than individuals with co-morbid conduct disorder and emotional disorder, as we assumed that working disability is specifically associated with ADHD.

As a diagnosis is only one component of the overall assessment process, and because symptoms and impairment are partly distinct dimensions that do not always correlate [7,26-28], a final issue was to examine whether the global assessment of psychosocial functioning in childhood could enhance outcome predictions.

\section{Methods}

\section{Study population}

The study population consisted of 258 child-psychiatric in-patients with intellectual level within the normal range. They were part of a larger study population consisting of all consecutively admitted in-patients $(n=550)$ at the children's unit at the National Centre for Child and Adolescent Psychiatry in Oslo (NCCAP), Norway, from January 1968 to October 1988. The complete study population has been described in detail elsewhere $[29,30]$. The children were admitted as in-patients because of their long lasting and complex problems. They were referred to the hospital from all over the country for assessment and in-patient treatment when local outpatient clinics were short of professional expertise. The children's unit at NCCAP provided specialized treatment for children up to 13 years. In the present study, individuals with emotional disorders, mixed disorder of conduct and emotions, conduct disorder and/or hyperkinetic disorders were included. Individuals with other psychiatric disorders and/or mental retardation $(n=292)$ were excluded. One person had emigrated before the age of 16 years, which was the youngest age for registration of a DP award in Norway during the study period, and was consequently excluded from the study. Thus, 257 participants were included in this study.

The gender distribution in the group was $82(32 \%)$ girls and 175 (68\%) boys. The mean age at admission was 8.7 years (SD 2. 3, range 2-13), with no gender differences. Fifty-six per cent of the patients were admitted to the family ward, $40 \%$ to the in-patients long-term ward and $4 \%$ to the day care ward. The mean length of stay was 1.1 months (SD 0.3, range 1-3) at the family ward, 8.2 months (SD 8.8, range 0.5-32) at the in- 
patients long-term ward and 24.4 months (SD 17.8, range $6-50)$ at the day-care ward. In total, $17 \%$ of the patients were admitted more than once. The mean age at follow-up (when those who had emigrated or died were excluded) was 36.9 years (SD 7.0, range 21-50), with a mean follow-up period of 28.2 years (SD 6.8, range 17-39). A total of 11 (4\%) participants had died and four $(2 \%)$ had emigrated.

\section{Outcome variables}

At follow-up in December 2005, the participants were identified by personal identification number in the population register at Statistics Norway. By record linkage, information about the DP award was obtained from Statistics Norway's events database FD-Trygd, which includes information from the Norwegian Labour and Welfare Organization. All citizens of Norway are eligible after 18 years of age (previously 16 years, until January $\left.1^{\text {st }} 1998\right)$ to be granted DP for an acknowledged medical condition that causes $>50 \%$ lasting reduction in work capacity. Entitlement to a DP is not means tested; it is solely a public responsibility.

The Norwegian Labour and Welfare Organization records information on all DP awards. Correct registration is a prerequisite for transfers of payment, and the records are thus highly accurate.

\section{Measures}

\section{Mental health (ICD-10)}

Based on all clinical information in the comprehensive hospital records, all the 257 patients were re-diagnosed according to the ICD-10 [31]. The diagnosis of greatest clinical importance (principal diagnosis) was pre-empted (Table 1). All the diagnoses were based on a consensus of two or more clinicians. (The diagnostic procedure has been described in more details in a previous report [29]).

\section{Children's Global assessment scale (CGAS)}

The children were reassessed on the CGAS, a global assessment of the child's psychosocial functioning [32], according to how they were described in the hospital records at the time of admission (Table 1). The CGAS is a widely used clinician-rated scale that assigns a single summary score from 1 to 100 , with 1 indicating the most severely disordered child and 100 the bestfunctioning child [32,33]. Anchors at 10-point intervals include descriptors of functioning for each interval. The instrument has been validated against many different psychiatric assessment scales [34], and it is good at distinguishing cases from non-cases $[35,36]$.

\section{Level of cognitive abilities}

An assessment of each participant's cognitive level was based on clinical findings and psychometric and pedagogic test results reported in the hospital records. For children of school age, teachers at NCCAP's affiliated school performed systematic pedagogic evaluations.

Diagnostic criteria for mental retardation were used according to the ICD-10. Only those patients with intellectual level in the normal range were included, as it was important to isolate the confounding effect of mental retardation when comparing diagnostic groups.

\section{Socio-demographic variables}

Gender was registered at baseline and reported in Table 1. Based on all the information available in the hospital records of the past and present family situation, we applied a global assessment of chronic family difficulties (CFD) [37]. Socio-economic conditions, social network, marital or family discord and current/previous physical and mental health of the family members were recorded. The total burden of difficulties was scored on an interval scale from 0 to 6 , with 0 indicating no sign of chronic family difficulties and a score of 6 indicating severe difficulties/very disturbed family environment (Table 1).

\section{Inter-rater study}

An inter-rater reliability study was carried out for the ICD-10 diagnoses, CGAS, CFD and cognitive level, and solid reliabilities were found [29].

Table 1 Distribution and descriptive characteristics of diagnostic groups at admission

\begin{tabular}{lcccccc}
\hline Diagnostic groups & CD & ADHD & ED & MCE & Total study population & ANOVA with post hoc* \\
\hline $\mathrm{N}$ & 39 & 53 & 98 & 67 & 257 & \\
\hline CGAS & $44.0(6.5)$ & $41.9(5.5)$ & $48.9(9.6)$ & $43.4(6.5)$ & $45.3(8.1)$ & $C D={ }^{b} A D H D=M C E<E D, p<0.05$ \\
\hline Age at admission & $8.9(1.7)$ & $8.0(2.3)$ & $8.9(2.7)$ & $8.8(1.9)$ & $8.7(2.3)$ & $P=0.13$ \\
\hline Male gender $^{a}$ & $31(80)$ & $44(83)$ & $52(53)$ & $48(72)$ & $175(68)$ & $E D<A D H D=C D=M C E, p<0.05$ \\
\hline CFD & $4.9(1.0)$ & $4.0(1.4)$ & $4.1(1.3)$ & $4.7(1.1)$ & $4.4(1.3)$ & $E D=A D H D<C D=M C E, p<0.05$ \\
\hline
\end{tabular}

ANOVA with post hoc analysis to provide differences between diagnostic groups.

*ANOVA post hoc if $\mathrm{p}<0.05$ in one-way Anova.

a Pearson's chi square/Fisher's exact test.

b non-significant differences.

$C D$, Conduct disorder; $A D H D$, Hyperkinetic disorder; ED, Emotional Disorder; MCE, Mixed disorder of conduct and emotions; CGAS, Children's Global Assessment Scale; CFD, Chronic family difficulties scale. 


\section{Statistical methods}

Categorical variables were examined using Pearson's chisquare test and Fisher's exact test, as appropriate. Continuous variables were examined using Student's two-sample $t$-test. A one-way ANOVA with a post-hoc comparison (Tukey) was conducted to explore differences in age, CFD and CGAS between diagnostic groups.

Possible associations between diagnostic groups and other characteristics of the children and a subsequent DP were tested using univariate survival analyses according to the Kaplan-Meier method and logrank testing. Using stratified logrank analyses, we examined the association between diagnosis and subsequent DP, adjusting for CGAS, CFD and gender.

In the survival analyses, participants were followed from the age of 16 years, which was the youngest age for registration of a DP during the study period, until a DP award was first registered, or otherwise, until their date of emigration, death, or follow-up in December 2005 for those who did not receive a DP. The study group was compared with the average Norwegian population in 2005 by using tables statistics [38]. SPSS version 18 was used for the statistical analyses.

\section{Ethics}

The study was approved by the Regional Committee of Ethics in Medical Research, the Department of Health and Social Services, and the Norwegian Data Inspectorate.

\section{Results}

\section{ICD-10 diagnostic groups}

Conduct disorder (CD) (F91) was diagnosed in 39 children (15\%) according to the ICD-10. Hyperkinetic disorder (ADHD) (F90) was diagnosed in 53 individuals (21\%), corresponding to the ADHD of combined type according to the DSM-IV criteria [39], except for three participants who fulfilled only the criteria for ADD. Thirty-two of these children (60\%) also met the criteria for conduct disorder (F90.1). Emotional disorder (ED) (including emotional disorders in childhood (F93), anxiety and other neurotic disorders (F40-F49), mood disorders (F30-F39), eating disorders (F50) and mutism (F94.0) was diagnosed in 98 children (38\%) according to the ICD-10. Mixed disorder of conduct and emotions (MCE) (F92) was diagnosed in 67 children $(26 \%)$ who met the criteria for both an emotional disorder and a conduct disorder.

Characteristics of the diagnostic groups are given in Table 1. With the exception of the emotional group, which had a greater percentage of females and higher CGAS scores at admission, there were no significant differences between diagnostic groups with regard to age, gender and CGAS score at admission.

\section{Disability pension award}

At follow-up, 49 persons (19\%) had received a DP award, with no significant gender differences (Table 2). The disability rate was markedly higher than the rate for the

Table 2 Vulnerability factors for disability pension award

\begin{tabular}{|c|c|c|c|c|}
\hline \multirow[t]{3}{*}{ Vulnerability factors } & \multirow[t]{3}{*}{$\mathrm{N}=257$} & DP & \multirow{3}{*}{$\frac{\text { Non-DP }}{\frac{N=208}{N(\%) / M e a n ~(S D) ~}}$} & \multirow{3}{*}{$\frac{\text { P-value }}{\text { Log- rank tes }}$} \\
\hline & & $\mathrm{N}=49$ & & \\
\hline & & $\overline{\mathrm{N}(\%) / \text { Mean (SD) }}$ & & \\
\hline \multicolumn{5}{|l|}{ Mental health (ICD-10) } \\
\hline$C D$ & 39 & $4(10)$ & $35(90)$ & 0.11 \\
\hline $\mathrm{ADHD}$ & 53 & $16(30)$ & $37(70)$ & 0.01 \\
\hline ADHD only & 21 & $5(24)$ & $16(76)$ & \\
\hline Co-morbid ADHD and CD & 32 & $11(34)$ & $21(66)$ & \\
\hline ED & 98 & 15(15) & $83(85)$ & 0.20 \\
\hline MCE & 67 & $14(21)$ & $53(79)$ & 0.61 \\
\hline CGAS & & & & $0.04^{a}$ \\
\hline CGAS $<40$ & 51 & $16(31)$ & $35(69)$ & \\
\hline CGAS 40-49 & 139 & $24(17)$ & 115(83) & \\
\hline CGAS $\geq 50$ & 67 & $9(13)$ & $58(87)$ & \\
\hline \multicolumn{5}{|l|}{ Sociodemographic variables } \\
\hline Male gender & 175 & $34(19)$ & $141(81)$ & 0.72 \\
\hline Female gender & 82 & 15(18) & $67(82)$ & \\
\hline CFD & 256 & $4.5(1.2)$ & $4.3(1.3)$ & 0.91 \\
\hline
\end{tabular}

Difference in prevalence of psychiatric disorders and other vulnerability factors between subjects who received disability pension (DP, N=49) and who did not receive DP (Non-DP, N=208) during the follow-up period. Significant $\mathrm{p}$-values of the logrank testing are given in bold.

${ }^{a}$ Logrank test with linear trend for factor levels.

$C D$, Conduct disorder; $A D H D$, Hyperkinetic disorder; $E D$, Emotional Disorder; $M C E$, Mixed disorder of conduct and emotions; CGAS, Children's Global Assessment Scale; CFD, Chronic family difficulties scale. 
same age groups in the general population, where a crude estimate was $5 \%$ [40]. The mean age when the DP was awarded was 22.8 years (SD 8.4, range 16-42) at the end of the follow-up.

\section{Vulnerability factors of the disability pension award}

The prevalence of DP awards and the p-value for the logrank test of diagnostic groups and other vulnerability factors are summarized in Table 2. Figures 1 and 2 show the Kaplan-Meier plots for variables most strongly related to receiving the DP award.

We made an overall diagnosis variable consisting of the four diagnostic categories (CD, ADHD, MCE and ED) to be used in the Kaplan-Meier and logrank analyses (Figure 1, Table 2). The diagnosis variable was significantly associated with a subsequent DP award $(\mathrm{p}=0.03)$. We also made one categorical variable for each diagnostic category: ADHD was the only disorder that was significantly associated with a subsequent DP, with $30 \%$ of these patients being disabled at follow-up $(p=0.01)$ (Table 2). When we split the ADHD group into those with ADHD only and those with ADHD and a comorbid conduct disorder, there were not enough patients in each group to predict DP awards separately for the two groups. The higher disability rate in the group with co-morbid conduct disorder did not differ significantly from the rate for the ADHD-only group (34\% vs. $24 \%$, $\mathrm{p}=0.54$, by Fischer's exact test). Our results thus suggest that co-morbid conduct disorder seemed to have no more than an additive effect. Similarly, there seemed to be no more than an additive effect for those with both

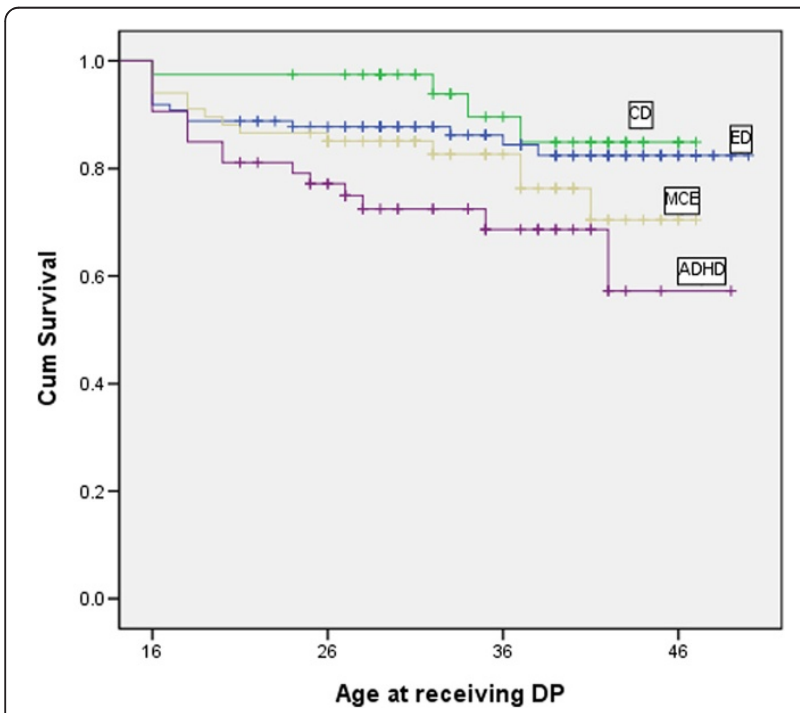

Figure 1 Kaplan-Meier curves depicting the age at receiving disability pension (DP) in patients with different ICD-10 diagnoses at admission. CD, Conduct disorder; ED, Emotional disorder; MCE, Mixed disorder of conduct and emotions; ADHD, Hyperkinetic disorder.

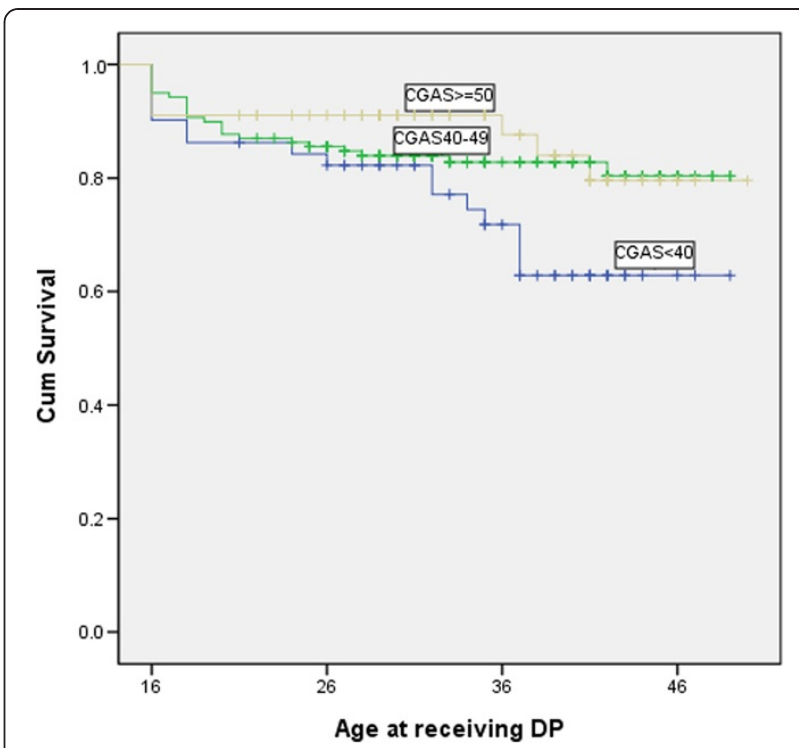

Figure 2 Kaplan-Meier curves depicting the age at receiving disability pension (DP) in patients with different Children's global assessment scale (CGAS) scores at admission.

emotional disorder and conduct disorder (MCE) relative to those who had either disorder alone (15\% vs. $21 \%$, $\mathrm{p}=0.35$, and $10 \%$ vs. $21 \%, \mathrm{p}=0.19$, by Pearson chi-square).

The CGAS score was condensed to a three-level score to be used in the Kaplan-Meier plot and in the logrank test with linear trends for factor levels (Figure 2, Table 2). The CGAS score at admission was significantly associated with a DP award at follow-up ( $p=0.04)$. Gender and CFD were not associated with a DP award.

To adjust for the different CGAS scores between diagnostic groups, we ran stratified logrank analyses in which the diagnostic groups were stratified by the CGAS three-level score. Hyperkinetic disorder was still the only diagnosis associated with a DP award (data not shown). We also ran logrank analyses in which the diagnostic groups were stratified by gender and CFD. The results did not change (data not shown). Lastly, the relationship between CGAS and DP remained similar when the analysis was stratified by diagnostic groups (data not shown).

\section{Discussion}

In this study, we compared the disability outcomes of ADHD patients with outcomes for patients with other externalizing and internalizing disorders. In line with our hypotheses, ADHD in childhood was highly associated with working disability in mid-adulthood, with the disability rate being highest when there was a co-morbid conduct disorder. We also found that individuals with co-morbid ADHD and conduct disorder were more disabled than were those with co-morbid emotional and conduct disorder, which reinforces the assumption that working disability is specifically associated with ADHD symptoms. 
Furthermore, assessment of psychosocial functioning at admission provided unique information about children at risk of a poor outcome.

\section{Disability pension award}

At the end of a 28-years study period, $19 \%$ of the individuals in this study had received a DP award, a markedly higher rate than that for the general population. As a DP award is most often a permanent benefit, awarded when treatment and extensive rehabilitation have failed, it is indicative of the severity of the work impairment these individuals have.

Our finding is in line with those from previous studies, which have shown that individuals with child and adolescent psychiatric disorders have disability rates ranging from $13 \%$ to $50 \%$ at follow-up [41-46]. Because mental retardation, organic disorders and pervasive developmental disorders are well-known predictors of DP [30,45,47], individuals with such disturbances were excluded in the present study. This probably explains the somewhat lower $\mathrm{DP}$ rate in our population relative to the $50 \% \mathrm{DP}$ rate found in two similar studies of adolescent in-patients, in which no such exclusions were performed [42,45]. However, all these studies present strong evidence for the relationship between severe psychiatric disorders in childhood and severe work impairment in adulthood.

\section{Vulnerability factors of the disability pension award ICD-10 disorders}

ADHD was the only disorder significantly associated with a subsequent DP award in the present study. The disability rate in the ADHD group was about twice that of groups with CD or ED, which suggests that work impairment is related to specific symptoms central to ADHD. Our finding thus extends previous research reporting this elevated risk for ADHD probands relative to non-clinical controls [11-13,48,49].

In two recent Norwegian studies of adult out-patients with ADHD, early intervention was an important predictor of being employed in adulthood [48,50]. Even though all of our patients received early intervention during hospitalization, their disability rate was markedly elevated and was as high as in these previous studies. However, our children were severely affected in-patients, and their poor outcome was probably influenced by their symptom severity. More than half of the children $(60 \%)$ had a co-morbid conduct disorder, and the prognosis for such individuals has been consistently reported to be even worse than for individuals with ADHD alone [24,51,52].

If we take the co-morbidity into account, it could perhaps be argued that the high rate of DP at follow-up, was a function of $\mathrm{CD}$ rather than childhood ADHD. However, CD alone or combined with ED was not associated with a DP award within this study population, and the DP rate was more than twice as high in the ADHD only group relative to the rate in the $\mathrm{CD}$ group. Thus, it seems that ADHD was the main contributor of the high DP rate found at follow-up, and that co-morbid CD had no more than an additive effect.

The lack of association between CD and DP is consistent with findings in previous follow-up studies of inpatients [45,47]. Similarly, a population-based study reported no association between employment difficulties and conduct problems when attention problems were adjusted for [53]. This gives support to the assumption of different aetiologies in ADHD and CD, underlying the neuropsychological characteristics of ADHD [2]. However, childhood CD has been consistently associated with delinquency [29,54-57], and many of these patients may have spent periods of their lives in prison. Consequently, the need for alternative financial support may have been reduced and/or these individuals' poor functioning has not been ascribed to disorders that give entitlement to a DP award. Worth noting, our individuals with CD had elevated DP rate relative to the rate in the general population. Previous research in less severe populations of out-patients and community samples has shown that early-onset conduct problems constitute a risk for a wide range of later adverse outcomes, which include mental health problems [58] and unemployment [59-61]. Considering all the serious implication of adult life in children with conduct problems, early intervention should be stressed to mitigate the poor prognosis.

In the present study, the combination of conduct disorder and emotional disorder appeared to be more disabling than either disorder alone. Our findings are thus consistent with previous research showing that individuals with co-morbid disorders have worse outcomes than those without [20,22]. Given the increased impairment in children with co-morbid disorders, accurate diagnosis and monitoring of co-morbidity are critical.

In line with our hypothesis, we found that individuals with combined ADHD and conduct disorder had a higher rate of DP than did those with combined emotional and conduct disorder, giving further support to the assumption that working disability is to some extend specifically associated with ADHD. The poor academic achievement reported for ADHD individuals may lead to low grade occupations $[62,63]$. DP has been found to be independently associated with low educational level [64]. Intensified treatment strategies that optimize school functioning could probably have significant contribution to promote educational attainment and later occupational functioning in this group.

\section{Children's Global assessment scale (CGAS)}

In this study, psychosocial impairment (assessed by CGAS score) was an important vulnerability factor for a 
DP award, even when adjusting for the presence of an ICD-10 disorder. Our finding illustrates the importance of evaluating both symptoms and functional impairment as part of a diagnostic assessment when studying an individual's developmental course. Attempts to link impairment to specific diagnoses have turned out to be difficult [27], and severity of symptoms and level of functioning have been claimed to be partly independent dimensions that do not always correlate [26,28]. Although the CGAS is problematic because symptoms and psychosocial impairment are conflated in a single scale score, our findings suggest that this global measure can identify individuals at risk of continuing problems decades later. Because the CGAS total score is correlated with an individual's overall psychosocial adjustment, it may promote more accurate prognoses than those assessments based on diagnostic features only.

\section{Socio-demographic variables (gender/CFD)}

In line with previous clinical research $[45,47]$, neither gender nor family difficulties (assessed by the chronic family difficulties scale, CFD) were associated with a subsequent DP award. Our failure to find an association between CFD and DP could be an artefact, however, because substantial family difficulties were reported for all of our children. In two recent Nordic population-based studies, unfavourable conditions in childhood, including family difficulties, were significantly associated with subsequent DP [65,66]. Likewise, in a four-year follow-up study of 140 ADHD children and 120 community controls, Biederman et al. found that family adversities were highly associated with a poor outcome (persistence of ADHD) [67]. We need further large-scale intervention studies to determine whether targeting family difficulties is likely to reduce the association between childpsychiatric patients and future DP.

\section{Strengths and limitations}

In this study, data were collected over a period varying from 17 to 39 years in a longitudinal follow-up study to examine the link between psychiatric disorders in childhood and a later DP award. The study's strengths are the long follow-up period and the relatively large number of patients included. It is a nationwide study, in which there should be no regional admission bias. Because of the egalitarian Norwegian society where all citizens are entitled the same health care system, the socio-economic position of the family was not the predominating factor when these patients were hospitalized.

The scoring was performed blind to outcome, as rediagnosis and scoring of the study population were completed before the outcome information was collected. The outcome variable, DP, is based on a high-quality national register.
This study has several limitations, however. All information was based on chart reviews from hospital records, which are not always reliable scientific sources. However, the hospital records were of good quality, giving a detailed and thorough description of the patients' symptoms, psychometric test results and family adversities. Experienced psychiatrists completed the re-diagnosis and scoring of the data from the study sample, and they ensured that consensus-based best-estimate diagnoses were made as accurately as possible according to the current ICD-10. Inter-rater reliability was high [29], in line with previous research, for which the validity of file-based diagnostic ratings has been found satisfactory $[68,69]$.

We have no estimate of the persistence of symptoms into adulthood in our children, but previous research has shown that symptom persistence is associated with symptom severity and co-morbidity in childhood $[67,70,71]$. Furthermore, adult disorders are often preceded by their juvenile counterparts [17]. However, because there were only two time points (i.e., childhood diagnoses and adult disability records) in the present study, we are restricted to reporting differences in prognosis across childhood diagnoses.

The DP award was the outcome measure in the present study, and this measure can never be sufficient to judge broader outcomes for individuals. However, the DP is an indicator of impairment in one major life activity that provides important information about adult outcomes.

Our group of individuals who were awarded the DP at follow-up provided insufficient statistical power to predict DP in single and co-morbid states of ADHD. Replication with larger groups is needed to predict DP in these subgroups separately.

Because we only had three individuals with ADD, we could not predict DP in the inattentive group relative to those with hyperactivity.

The factors identified in this study are not causative, but they should be considered as possible vulnerability factors that increase the risk of receiving a DP in an inpatient population. It is important to realize that this population consisted of severe cases that might have worsened the long-term outcome, and the results cannot immediately be generalized to out-patients. As criteria for obtaining DP vary considerably between countries, generalization of the findings is limited to nations with similar welfare systems.

\section{Conclusions}

In this longitudinal study of child-psychiatric in-patients, we found that working ability was severely affected in mid-adulthood. ADHD appeared to be specifically linked to working disability compared with other externalizing and internalizing disorders. Considering the early onset and often chronic course of ADHD, direct primary 
prevention programs in preschools and schools should be endeavoured to mitigate academic underachievement. Given the increased impairment in children with comorbid conduct disorder, early targeting of conduct problems should be emphasized. Regardless of diagnostic features, the assessment of psychosocial functioning could improve identifying children being most at risk of future disability. The chronic course and high rate of disability in child-psychiatric in-patients illuminate the importance of improving early intervention among such patients. Further research is highly needed to identify factors preventing long-term disability.

\section{Abbreviations}

MM: Marianne Mordre; BG: Berit Groholt; BS: Berit Sandstad; AMM: Anne Margrethe Myhre.

\section{Competing interests}

The authors declare that they have no competing interests.

\section{Authors' contributions}

All authors (except BS) conceived of and designed the study. MM participated in the collection of data, performed statistical analyses and drafted the first manuscript. BG participated in the collection of data, helped with statistical analyses and made significant contribution to the final draft. BS made significant contribution to the statistically analyses and critically reviewed the manuscript. AMM participated in the collection of data, made significant contribution to the final draft and supervised the work and critically reviewed the manuscript. All authors read and approved the final manuscript.

\section{Acknowledgements}

We gratefully acknowledge Eili Sponheim, Ingrid Spurkland and Inger Helene Vandvik for their participation in recoding hospital records and for their crucial role in initiating and supporting the accomplishment of the study. We also want to thank Ann Kristin Knudsen and Arnstein Mykletun for assistance in the translation of the database FD-trygd

\section{Author details}

'Division of Mental Health and Addiction, Oslo University Hospital, P.O. Box 4959, Nydalen, 0424 Oslo, Norway. ${ }^{2}$ Institute for Clinical Medicine, University of Oslo, Oslo, Norway. ${ }^{3}$ Unit of Biostatistics and Epidemiology, Oslo University Hospital, Oslo, Norway. ${ }^{4}$ Division of Mental Health and Addiction, Oslo University Hospital, Norway and Institute for Clinical Medicine, University of Oslo, Oslo, Norway.

Received: 11 January 2012 Accepted: 16 October 2012 Published: 19 October 2012

\section{References}

1. Barkley RA, Grodzinsky G, DuPaul GJ: Frontal lobe functions in attention deficit disorder with and without hyperactivity: a review and research report. J Abnorm Child Psychol 1992, 20:163-188.

2. Clark C, Prior M, Kinsella GJ: Do executive function deficits differentiate between adolescents with ADHD and oppositional defiant/conduct disorder? a neuropsychological study using the Six Elements Test and Hayling Sentence Completion Test. J Abnorm Child Psychol 2000, 28:403-414

3. Fergusson DM, Lynskey MT, Horwood LJ: Attentional difficulties in middle childhood and psychosocial outcomes in young adulthood. J Child Psychol Psychiatry 1997, 38:633-644.

4. Fergusson DM, Horwood LJ: Early disruptive behavior, IQ, and later schoo achievement and delinquent behavior. J Abnorm Child Psychol 1995 23:183-199.

5. Pardini DA, Fite PJ: Symptoms of conduct disorder, oppositional defiant disorder, attention-deficit/hyperactivity disorder, and callousunemotional traits as unique predictors of psychosocial maladjustment in boys: advancing an evidence base for DSM-V. J Am Acad Child AdolesC Psychiatry 2010, 49:1134-1144.

6. Barkley RA, Fischer M, Smallish L, Fletcher K: Young adult outcome of hyperactive children: adaptive functioning in major life activities. J Am Acad Child Adolesc Psychiatry 2006, 45:192-202.

7. Mannuzza S, Castellanos FX, Roizen ER, Hutchison JA, Lashua EC, Klein RG: Impact of the impairment criterion in the diagnosis of adult ADHD: 33-year follow-up study of boys with ADHD. J Atten Disord 2011, 15:122-129.

8. Rasmussen P, Gillberg C: Natural outcome of ADHD with developmental coordination disorder at age 22 years: a controlled, longitudinal, community-based study. J Am Acad Child Adolesc Psychiatry 2000, 39:1424-1431.

9. Weiss G, Hechtman L, Milroy T, Perlman T: Psychiatric status of hyperactives as adults: a controlled prospective 15-year follow-up of 63 hyperactive children. J Am Acad Child Psychiatry 1985, 24:211-220.

10. Davidson MA: ADHD in adults: a review of the literature. J Atten Disord 2008, 11:628-641.

11. Able SL, Johnston JA, Adler LA, Swindle RW: Functional and psychosocial impairment in adults with undiagnosed ADHD. Psychol Med 2007, 37:97-107.

12. Biederman J, Faraone SV, Spencer TJ, Mick E, Monuteaux MC, Aleardi M: Functional impairments in adults with self-reports of diagnosed ADHD: a controlled study of 1001 adults in the community. J Clin Psychiatry 2006, 67:524-540.

13. Kessler RC, Lane M, Stang PE, Van Brunt DL: The prevalence and workplace costs of adult attention deficit hyperactivity disorder in a large manufacturing firm. Psychol Med 2009, 39:137-147.

14. Barkley RA, Fischer M, Smallish L, Fletcher K: The persistence of attention-deficit/hyperactivity disorder into young adulthood as a function of reporting source and definition of disorder. J Abnorm Psychol 2002, 111:279-289.

15. Mannuzza S, Klein RG: Long-term prognosis in attention-deficit/ hyperactivity disorder. Child Adolesc Psychiatr Clin N Am 2000, 9:711-726.

16. Harrington R, Fudge $H$, Rutter M, Pickles A, Hill J: Adult outcomes of childhood and adolescent depression: II. Links with antisocial disorders. J Am Acad Child Adolesc Psychiatry 1991, 30:434-439.

17. Kim-Cohen J, Caspi A, Moffitt TE, Harrington H, Milne BJ, Poulton R: Prior juvenile diagnoses in adults with mental disorder: developmental follow-back of a prospective-longitudinal cohort. Arch Gen Psychiatry 2003, 60:709-717

18. Moffitt TE, Caspi A, Harrington H, Milne BJ: Males on the life-course-persistent and adolescence-limited antisocial pathways: follow-up at age 26 years. Dev Psychopathol 2002, 14:179-207.

19. Fombonne E, Wostear G, Cooper V, Harrington R, Rutter M: The Maudsley long-term follow-up of child and adolescent depression. 1. Psychiatric outcomes in adulthood. Br J Psychiatry 2001, 179:210-217.

20. Renouf AG, Kovacs M, Mukerji P: Relationship of depressive, conduct, and comorbid disorders and social functioning in childhood. J Am Acad Child Adolesc Psychiatry 1997, 36:998-1004.

21. Fischer M, Barkley RA, Smallish L, Fletcher K: Young adult follow-up of hyperactive children: self-reported psychiatric disorders, comorbidity, and the role of childhood conduct problems and teen CD. J Abnorm Child Psychol 2002, 30:463-475.

22. Sourander A, Jensen P, Davies M, Niemela S, Elonheimo H, Ristkari T, et al: Who is at greatest risk of adverse long-term outcomes? The Finnish From a Boy to a Man study. J Am Acad Child Adolesc Psychiatry 2007, 46:1148-1161.

23. Barkley RA, Cunningham CE, Gordon M, Faraone SV, Lewandowski L, Murphy KR: ADHD symptoms vs. impairment: revisited. ADHD 2006, 14:1-9.

24. Wilson JM, Marcotte AC: Psychosocial adjustment and educational outcome in adolescents with a childhood diagnosis of attention deficit disorder. J Am Acad Child Adolesc Psychiatry 1996, 35:579-587.

25. Young S, Toone B, Tyson C: Comorbidity and psychosocial profile of adults with attention deficit hyperactivity disorder. Person individ Diff 2002, 35:743-755.

26. Angold A, Costello EJ, Farmer EM, Burns BJ, Erkanli A: Impaired but undiagnosed. J Am Acad Child Adolesc Psychiatry 1999, 38:129-137.

27. Bird HR, Davies M, Fisher P, Narrow WE, Jensen PS, Hoven C, et al: How specific is specific impairment? J Am Acad Child Adolesc Psychiatry 2000 39:1182-1189. 
28. Gordon M, Antshel K, Faraone S, Barkley R, Lewandowski L, Hudziak JJ, et al: Symptoms versus impairment: the case for respecting DSM-IV's Criterion D. J Atten Disord 2006, 9:465-475.

29. Mordre M, Groholt B, Kjelsberg E, Sandstad B, Myhre AM: The impact of $\mathrm{ADHD}$ and conduct disorder in childhood on adult delinquency: a 30 years follow-up study using official crime records. BMC Psychiatry 2011 11:57.

30. Mordre M, Groholt B, Knudsen AK, Sponheim E, Mykletun A, Myhre AM: Is Long-Term Prognosis for Pervasive Developmental Disorder Not Otherwise Specified Different from Prognosis for Autistic Disorder? Findings from a 30-Year Follow-Up Study. J Autism Dev Disord 2012, 42:920-928.

31. World Health Organization: The ICD-10 classification of mental health and behavioural disorders (ICD-10). Clinical descriptions and diagnostic guidelines. Geneva: World Health organization; 1992.

32. Shaffer D, Gould MS, Brasic J, Ambrosini P, Fisher P, Bird H, et al: A children's global assessment scale (CGAS). Arch Gen Psychiatry 1983, 40:1228-1231

33. Bird HR, Andrews H, Schwab-Stone M, Goodman S, Dulcan M, Richters J, et al: Global measures of impairment for epidemiologic and clinical use with children and adolescents. Int J Methods Psychiatr Res 1996, 6:295-307.

34. Winters NC, Collett BR, Myers KM: Ten-year review of rating scales, VII: scales assessing functional impairment. J Am Acad Child Adolesc Psychiatry 2005, 44:309-338.

35. Bird HR, Canino G, Rubio-Stipec M, Ribera JC: Further measures of the psychometric properties of the Children's Global Assessment Scale. Arch Gen Psychiatry 1987, 44:821-824.

36. Bird HR, Yager TJ, Staghezza B, Gould MS, Canino G, Rubio-Stipec M: Impairment in the epidemiological measurement of childhood psychopathology in the community. J Am Acad Child Adolesc Psychiatry 1990, 29:796-803.

37. Vandvik $\mathrm{H}$, Hoyeraal $\mathrm{HM}$, Fagertun $\mathrm{H}$ : Chronic family difficulties and stressful life events in recent onset juvenile arthritis. J Rheumatol 1989, 16:1088-1092.

38. StatBank Norway. 2005. Retrieved from http://statbank.ssb.no/ statistikkbanken

39. American Psychiatric Association: Diagnostic and statistical manual of mental disorders, text revised(DSM-IV-TR) edition. Washington, DC: American Psychiatric association; 2000.

40. The Norwegian Labour and Welfare Administration. 2005. Retrieved from http://www.nav.no/805323065.cms.

41. Gillberg IC, Hellgren L, Gillberg C: Psychotic disorders diagnosed in adolescence. Outcome at age 30 years. J Child Psychol Psychiatry 1993, 34:1173-1185

42. Kjelsberg E, Dahl AA: High delinquency, disability and mortality-a register study of former adolescent psychiatric in-patients. Acta Psychiatr Scand 1998, 98:34-40.

43. Larsen FW, Dahl V, Hallum E: A 30 years follow-up study of a child psychiatric clientele. I. Demographic description. Acta Psychiatr Scand 1990, 81:39-45.

44. Ostman O: Child and adolescent psychiatric patients in adulthood. Acta Psychiatr Scand 1991, 84:40-45.

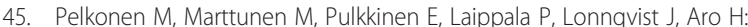
Disability pensions in severely disturbed in-patient adolescents. Twenty-year prospective study. Br J Psychiatry 1998, 172:159-163.

46. Werry JS, McClellan JM, Chard L: Childhood and adolescent schizophrenic, bipolar, and schizoaffective disorders: a clinical and outcome study. J Am Acad Child Adolesc Psychiatry 1991, 30:457-465.

47. Kjelsberg E: A long-term follow-up study of adolescent psychiatric in-patients. Part III. Predictors of disability. Acta Psychiatr Scand 1999, 99:243-246.

48. Halmoy A, Fasmer OB, Gillberg C, Haavik J: Occupational outcome in adult ADHD: impact of symptom profile, comorbid psychiatric problems, and treatment: a cross-sectional study of 414 clinically diagnosed adult ADHD patients. J Atten Disord 2009, 13:175-187.

49. Mannuzza S, Klein RG, Bessler A, Malloy P, Hynes ME: Educational and occupational outcome of hyperactive boys grown up. J Am Acad Child Adolesc Psychiatry 1997, 36:1222-1227.

50. Gjervan B, Torgersen T, Nordahl HM, Rasmussen K: Functional Impairment and Occupational Outcome in Adults With ADHD. J Atten Disord 2012, 16:544-552.
51. Dalsgaard S, Mortensen PB, Frydenberg M, Thomsen PH: Conduct problems, gender and adult psychiatric outcome of children with attention-deficit hyperactivity disorder. Br J Psychiatry 2002, 181:416-421.

52. Newcorn JH, Miller SR, Ivanova I, Schulz KP, Kalmar J, Marks DJ, et al: Adolescent outcome of ADHD: impact of childhood conduct and anxiety disorders. CNS Spectr 2004, 9:668-678.

53. Fergusson DM, Horwood LJ, Ridder EM: Show me your child at seven: the consequences of conduct problems in childhood for psychosocial functioning in adulthood. J Child Psychol Psychiatry 2005, 46:837-849.

54. Barkley RA, Fischer M, Smallish L, Fletcher K: Young adult follow-up of hyperactive children: antisocial activities and drug use. J Child Psychol Psychiatry 2004, 45:195-211.

55. Farrington DP: Implications of criminal career research for the prevention of offending. J Adolesc 1990, 13:93-113.

56. Kjelsberg E, Dahl AA: A long-term follow-up study of adolescent psychiatric in-patients. Part II. Predictors of delinquency. Acta Psychiatr Scand 1999, 99:237-242.

57. Satterfield JH, Faller KJ, Crinella FM, Schell AM, Swanson JM, Homer LD: A 30-year prospective follow-up study of hyperactive boys with conduct problems: adult criminality. J Am Acad Child Adolesc Psychiatry 2007, 46:601-610.

58. Storm-Mathisen A, Vaglum P: Conduct disorder patients 20 years later: a personal follow-up study. Acta Psychiatr Scand 1994, 89:416-420.

59. Brook JS, Newcomb MD: Childhood aggression and unconventionality: impact on later academic achievement, drug use, and workforce involvement. J Genet Psychol 1995, 156:393-410.

60. Fergusson DM, Horwood LJ: Early conduct problems and later life opportunities. J Child Psychol Psychiatry 1998, 39:1097-1108.

61. Zoccolillo M, Pickles A, Quinton D, Rutter M: The outcome of childhood conduct disorder: implications for defining adult personality disorder and conduct disorder. Psychol Med 1992, 22:971-986.

62. Galera C, Melchior M, Chastang JF, Bouvard MP, Fombonne E: Childhood and adolescent hyperactivity-inattention symptoms and academic achievement 8 years later: the GAZEL Youth study. Psychol Med 2009, 39:1895-1906.

63. Galera C, Bouvard MP, Lagarde E, Michel G, Touchette E, Fombonne E, et al: Childhood attention problems and socioeconomic status in adulthood: 18-year follow-up. Br J Psychiatry 2012, 201:20-25.

64. Bruusgaard D, Smeby L, Claussen B: Education and disability pension: a stronger association than previously found. Scand J Public Health 2010, 38:686-690.

65. Harkonmaki K, Korkeila K, Vahtera J, Kivimaki M, Suominen S, Sillanmaki L, et al: Childhood adversities as a predictor of disability retirement. J Epidemiol Community Health 2007, 61:479-484.

66. Upmark M, Thundal KL: An explorative, population-based study of female disability pensioners: the role of childhood conditions and alcohol abuse/dependence. Scand J Public Health 2002, 30:191-199.

67. Biederman J, Faraone S, Milberger S, Curtis S, Chen L, Marrs A, et al: Predictors of persistence and remission of ADHD into adolescence: results from a four-year prospective follow-up study. J Am Acad Child Adolesc Psychiatry 1996, 35:343-351

68. Grann M, Langstrom N, Tengstrom A, Stalenheim EG: Reliability of file-based retrospective ratings of psychopathy with the PCL-R. J Pers Assess 1998, 70:416-426.

69. McKenzie K, Scott DA, Waller GS, Campbell M: Reliability of routinely collected hospital data for child maltreatment surveillance. BMC Public Health 2011, 11:8.

70. Kessler RC, Adler LA, Barkley R, Biederman J, Conners CK, Faraone SV, et al: Patterns and predictors of attention-deficit/hyperactivity disorder persistence into adulthood: results from the national comorbidity survey replication. Biol Psychiatry 2005, 57:1442-1451.

71. Lara C, Fayyad J, De GR, Kessler RC, Aguilar-Gaxiola S, Angermeyer M, et al: Childhood predictors of adult attention-deficit/hyperactivity disorder: results from the World Health Organization World Mental Health Survey Initiative. Biol Psychiatry 2009, 65:46-54.

doi:10.1186/1471-244X-12-174

Cite this article as: Mordre et al:: The impact of ADHD symptoms and global impairment in childhood on working disability in mid-adulthood: a 28-year follow-up study using official disability pension records in a high-risk in-patient population. BMC Psychiatry 2012 12:174. 